\title{
Efficacy and patient satisfaction after NovaSure and Minerva endometrial ablation for treating abnormal uterine bleeding: a retrospective comparative study
}

This article was published in the following Dove Press journal: International Journal of Women's Health

\author{
Constantine Scordalakes' \\ Robert delRosario ${ }^{2}$ \\ Andrew Shimer ${ }^{3}$ \\ Russell Stankiewicz ${ }^{4}$ \\ 'Women's Health Care, P.C., \\ Newburgh, IN, 'Partners in Women's \\ Healthcare, Lemoyne, PA, ${ }^{3} \mathrm{Craig}$ \\ Ranch OB-GYN, McKinney, TX, \\ ${ }^{4} \mathrm{OB}-\mathrm{GYN}$ of Evangelical, Lewisburg, \\ PA, USA
}

Objective: Compare amenorrhea rate, menstrual symptoms, patient satisfaction, and adverse events in women who underwent endometrial ablation with the NovaSure versus the Minerva radiofrequency ablation systems.

Methods: We surveyed 189 premenopausal women (mean $40.8 \pm 6.2$ years old) who underwent endometrial ablation for abnormal uterine bleeding using the NovaSure $(n=97)$ or Minerva $(\mathrm{n}=92)$ systems, at four private US gynecology clinics, and whose procedure date was after July 2015 with follow-up $\geq 3$ months. Women were surveyed an average of $11.3 \pm 3.9$ months (range 137-532 days) after ablation.

Results: The subject-reported amenorrhea rate was $52 \%$ higher in NovaSure subjects than Minerva subjects ( $64 \%$ and $42 \%$, respectively; $p=0.004)$. Age and bleeding cyclicity did not affect amenorrhea rate in either group. Normal-to-no bleeding was reported by $>90 \%$ of subjects after either treatment. NovaSure was significantly more effective than Minerva at reducing pad/tampon use in women with any residual bleeding ( $2.4 \pm 5.2$ items/day versus $4.7 \pm 5.5$ items/day, $p=0.049)$. NovaSure was significantly more effective than Minerva at reducing premenstrual syndrome (PMS) symptoms $(p=0.019)$ and menstrual pain $(p=0.003)$, and more NovaSure subjects $(94 \%)$ than Minerva subjects ( $78 \%)$ were satisfied with clinical outcomes $(p=0.003)$. Adverse events did not differ by treatment; three women in each group progressed to hysterectomy.

Conclusion: While overall bleeding reduction in premenopausal women with abnormal uterine bleeding was excellent with either endometrial ablation system, NovaSure treatment resulted in a higher patient-reported 1-year amenorrhea rate, and women with residual bleeding used fewer pads and tampons than Minerva-treated women. Additionally, NovaSure subjects reported better menstrual-related life quality and PMS symptom alleviation, and greater satisfaction with outcomes than Minerva-treated women.

Keywords: endometrial ablation, abnormal uterine bleeding, NovaSure, Minerva, premenopausal, satisfaction

\section{Plain language summary}

NovaSure-treated women reported a higher 1-year amenorrhea rate, better quality of life, and greater satisfaction versus Minerva-treated women. Bleeding reduction in women with abnormal uterine bleeding was excellent with either endometrial ablation system.

\section{Introduction}

Abnormal uterine bleeding (AUB) affects up to $30 \%$ of premenopausal women, ${ }^{1}$ and negatively impacts quality of life (QoL). ${ }^{2}$ Medical treatment of AUB is frequently effective, but the accumulative costs and potential adverse effects (AEs) associated with long-term medical therapy restrict patient adherence. ${ }^{3}$ Hysterectomy can decisively treat
Correspondence: Constantine Scordalakes

Women's Health Care, P.C., 4199

Gateway Blvd, Ste 2450, Newburgh,

IN 47630, USA

Tel +l 8128584600

Email cscordalakes@whcpc.com 
AUB if medical therapy fails or is contraindicated, but it is an aggressive approach that carries risk of serious short-term complications such as wound infection, sepsis, and surgical trauma to nearby nontarget tissues, and longer-term AEs such as pelvic organ prolapse, urinary incontinence, and increased risk of cardiovascular disease. ${ }^{4-6}$ Endometrial ablation is an effective but less-invasive surgical option for treating AUB, using either resectoscopy or newer second-generation techniques that deliver high-dose radio, thermal, or microwave energy to uniformly destroy the entire uterine lining. ${ }^{7-9}$

The NovaSure ${ }^{\circledR}$ radiofrequency (RF) endometrial ablation system (Hologic Inc., Marlborough, MA, USA) has been used in the USA to treat AUB since 2001, when it received US Food and Drug Administration (FDA) approval (P010013), ${ }^{10}$ and was available before that time in Europe, Canada, and Australia. The Minerva ${ }^{\mathrm{TM}}$ ablation system (Minerva Surgical Inc., Redwood City, CA, USA) received FDA approval to treat AUB more recently, in July 2015. ${ }^{11}$ The current multicenter study directly compared amenorrhea rates and patient satisfaction levels in premenopausal women who since July 2015 underwent either NovaSure or Minerva endometrial ablation to treat AUB.

\section{Methods and materials \\ Study design and patients}

This retrospective case series chart review and prospective telephone survey assessed amenorrhea rate and bleeding severity changes, reinterventions, perioperative AEs, and patient satisfaction in premenopausal women who underwent endometrial ablation with either the NovaSure or Minerva systems for AUB. Study sites were four private US gynecology clinics that performed both procedures. All procedures were performed between October 2015 and November 2016. Surveys occurred in March/April 2017. All aspects of this research were approved by Quorum Review Institutional Review Board (IRB; Seattle, WA, USA), including a waiver of informed consent for chart review of de-identified patient data, and also verbal consent prior to survey participation. Subjects provided verbal informed consent before being surveyed. Subjects were mailed a Participant Letter that detailed the study objective, design, potential risks, investigator contact information, anticipated time commitment and compensation, and guarantee of confidentiality and IRB oversight, with an invitation to participate, at least 1 week before attempting telephone contact. The Participant Letter and the uniformly administered Survey Script were both preapproved by the IRB. This investigation complied with the Declaration of Helsinki and the Health Insurance Portability and Accountability Act of 1996. All aspects of study reporting conform to the Strengthening The Reporting of
OBservational studies in Epidemiology (STROBE) statement and criteria (https://www.strobe-statement.org).

\section{Study criteria}

Enrollment criteria: 1) Premenopausal women $\geq 18$ years old; 2) AUB history; 3) completed desired child-bearing; 4) underwent attempted/completed endometrial ablation with the Minerva or NovaSure systems after July 2015; and 5 ) had documented follow-up $\geq 3$ months. Exclusion criteria comprised contraindications-to-use from the packaging information of each device. We targeted a protocol-defined 1:1 Minerva/NovaSure cohort. All sites used both surgical devices. We assumed that there would be fewer Minerva vs NovaSure subjects in general across study sites because of its relatively new introduction. Therefore, at each study site we enrolled all Minerva subjects and an equivalent number of NovaSure subjects. We conscientiously strived to numerically and temporally (time from procedure to query) match both study arms, so long as all participants met study criteria. Once all Minvera patients and an equivalent number of NovaSure subjects had been enrolled at each site, no further enrollment occurred (only excess NovaSure subjects remained). This maintained a pre-established 1:1 subject ratio. No subject's post-procedure bleeding status was reviewed, queried, nor known at enrollment, in either study arm.

\section{NovaSure device}

The NovaSure Impedance Controlled Endometrial Ablation System was FDA-approved in 2001 for treating AUB. ${ }^{10}$ The disposable NovaSure device contains a bipolar RF electrode array mounted onto an expandable frame that conforms to the interior uterine wall. The array's porous metalicized fabric allows continuous removal of blood, moisture, and generated steam. The RF controller delivers the precise current required for uniform-depth ablation until $50 \Omega$ tissue impedance is reached or 2 minutes elapses, whichever occurs first. Carbon dioxide is delivered into the uterus preoperatively to confirm uterine wall integrity.

\section{Minerva device}

The Minerva system was FDA-approved in 2015 to treat AUB. ${ }^{11}$ The Minerva system also uses a disposable handpiece. Bipolar RF electrical current ionizes argon gas contained within a balloon into plasma, delivering thermal energy to the adjacent endometrium; heated intracavitary moisture and a small amount of bipolar RF current provide further ablation. Ablation is for a constant, 2-minute duration. A uterine integrity test is employed preoperatively to identify uterine-wall defects. 


\section{Outcome measures}

The primary efficacy outcome was the percent of subjects experiencing amenorrhea at $\geq 3$ postoperative months. Secondary efficacy outcomes were change in AUB symptom severity from baseline, percentage of subjects requiring secondary intervention (medical or surgical) for recalcitrant AUB, and patient satisfaction. Technical success was defined as satisfactory completion of endometrial ablation, and clinical success was achieving normal-to-no bleeding. The primary safety-related outcome was perioperative AE incidence.

\section{Statistics}

Categorical variables were assessed with Fisher's exact test. Continuous variables were compared by Student's $t$-test.
For all tests, two-tailed $p$-values $<0.05$ indicated statistically significant differences. Analyses used Excel 2010 (Microsoft Corp., Redmond, WA, USA) and Prism v.5.03 (GraphPad Software Inc., San Diego, CA, USA).

\section{Results}

Of 274 women who had undergone endometrial ablation using either NovaSure or Minerva systems since July 2015 and were contacted by telephone, 208 women (76\%) agreed to participate in the study and were enrolled. The 66 nonparticipants included 37 Minerva (56\%) and 29 NovaSure subjects (44\%). Of all 208 volunteers, 19 subjects did not satisfy all study inclusion criteria and were excluded from analysis; reasons included insufficient documentation of

Table I Demographics and OB/GYN history

\begin{tabular}{|c|c|c|c|c|}
\hline Parameter & NovaSure $(n=97)$ & Minerva $(n=92)$ & $p$-value ${ }^{a}$ & Total $(n=189)$ \\
\hline \multicolumn{5}{|l|}{ Age, years } \\
\hline Mean \pm SD & $40.4 \pm 6.1$ & $4 I .1 \pm 6.2$ & 0.4351 & $40.8 \pm 6.2$ \\
\hline Median (range) & $40.4(28-55)$ & $41.1(23-54)$ & & $27.8(23-55)$ \\
\hline \multicolumn{5}{|l|}{ Race, n (\%) } \\
\hline White & $91(94)$ & $85(92)$ & 0.7784 & $176(93)$ \\
\hline Asian & $0(0)$ & $2(2)$ & & $2(I)$ \\
\hline Black/African-American & $3(3)$ & $3(3)$ & & $6(3)$ \\
\hline Not reported/unknown & $3(3)$ & $2(2)$ & & $4(2)$ \\
\hline \multicolumn{5}{|l|}{ Ethnicity, n (\%) } \\
\hline Not Hispanic/Latino & $91(94)$ & $82(92)$ & 0.3009 & $173(92)$ \\
\hline Hispanic/Latino & $I(I)$ & $2(2)$ & & $3(2)$ \\
\hline Not reported/unknown & $5(5)$ & $8(9)$ & & $13(7)$ \\
\hline \multicolumn{5}{|l|}{ Body measurements } \\
\hline Height, $\mathrm{cm}$, mean \pm SD & $165 \pm 7$ & $165 \pm 6$ & 0.9999 & $165 \pm 7$ \\
\hline Median (range) & $164(147-183)$ & $165(152-180)$ & & $165(147-183)$ \\
\hline Weight, kg, mean \pm SD & $77.0 \pm 17.7(n=96)$ & $82.3 \pm 22.8(n=91)$ & 0.0766 & $79.6 \pm 20.5(n=187)$ \\
\hline Median (range) & $76.0(47.6-143.8)$ & $77.6(47.6-143.3)$ & & $76.7(47.6-143.8)$ \\
\hline $\mathrm{BMI}, \mathrm{kg} / \mathrm{m}^{2}$, mean $\pm \mathrm{SD}$ & $28.3 \pm 5.9(n=96)$ & $30.2 \pm 8.3(n=91)$ & 0.0702 & $29.2 \pm 7.2(n=187)$ \\
\hline Median (range) & $27.8(19.1-43.0)$ & $27.7(17.6-56.9)$ & & $27.8(17.6-56.9)$ \\
\hline \multicolumn{5}{|l|}{ Gravidity, n } \\
\hline Mean \pm SD & $2.8 \pm 1.4$ & $2.7 \pm 1.6$ & 0.6476 & $2.8 \pm 1.5$ \\
\hline Median (range) & $3(0-8)$ & $2(0-9)$ & & $0-9$ \\
\hline \multicolumn{5}{|l|}{ Parity, n } \\
\hline Mean \pm SD & $2.2 \pm 0.9$ & $2.0 \pm 1.1$ & 0.1720 & $2.1 \pm 1.0$ \\
\hline Median (range) & $2(0-5)$ & $2(0-7)$ & & $2(0-7)$ \\
\hline \multicolumn{5}{|l|}{ Menstrual cyclicity, n (\%) } \\
\hline Cyclic heavy bleeding & 77 (79) & $70(76)$ & $0.604 I$ & 147 (78) \\
\hline Noncyclic heavy bleeding & $6(6)$ & $8(9)$ & 0.5852 & $14(7)$ \\
\hline Both cyclic and noncyclic bleeding & $14(14)$ & $14(15)$ & 0.9999 & $28(15)$ \\
\hline \multicolumn{5}{|l|}{ Prior procedures, n (\%) } \\
\hline Hysteroscopy & $4(4)$ & $4(4)$ & 0.9999 & $8(4)$ \\
\hline $\mathrm{D} \& \mathrm{C}$ & $9(9)$ & $15(16)$ & 0.1906 & $24(13)$ \\
\hline Laparoscopy & $6(6)$ & $2(2)$ & 0.2831 & $8(4)$ \\
\hline Contraceptive sterilization & $43(44)$ & $42(46)$ & 0.8844 & $85(45)$ \\
\hline Hysteroscopic & $7(7)$ & $10(9)$ & 0.4505 & $17(9)$ \\
\hline Laparoscopic & $28(29)$ & $28(30)$ & 0.8739 & $56(30)$ \\
\hline Tubal with C-section & $5(5)$ & $3(3)$ & 0.7214 & $8(4)$ \\
\hline Other/not specified & $3(3)$ & $\mathrm{I}(\mathrm{I})$ & 0.6209 & $4(2)$ \\
\hline
\end{tabular}

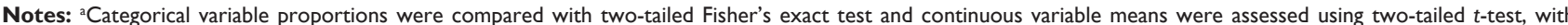
$p$-values calculated before rounding measured values to a single decimal place. Percentage values were rounded to nearest integer and do not necessarily total $100 \%$. Abbreviations: BMI, body mass index; D\&C, dilation and curettage; OB/GYN, obstetrics and gynecology. 
AUB status, being postmenopausal, and having undergone ablation outside of the protocol-defined window. The final evaluable cohort $(\mathrm{N}=189)$ included 97 NovaSure subjects and 92 Minerva subjects, an approximate 1:1 ratio. All subjects had provided verbal informed consent before completing the telephone survey.

No demographic or gynecological historical parameter significantly differed between NovaSure and Minerva subjects (Table 1). Mean participant age at intervention was $40.8 \pm 6.2$ years, 93\% of subjects self-identified as White, and $2 \%$ of women self-reported Hispanic ethnicity. Mean body mass index was 29.2 \pm 7.2 . Gynecologic and obstetric histories were similar in both groups, with $45 \%$ of the cohort having undergone a contraceptive sterilization procedure. Women in both arms had similar bleeding patterns; 78\% had cyclic heavy menstrual bleeding, 7\% experienced noncyclic bleeding, and 15\% reported both cyclic and noncyclic bleeding. There was no difference between NovaSure and Minerva subjects with respect to intrauterine pathology; approximately $2 \%$ of women were noted to have polyps and $10 \%$ had fibroids (Table 2).
No differences in preablation diagnostic assessments existed between the NovaSure and Minerva treatment groups (Table 2). There were no disparities in the types of anesthesia used between the two groups, with $74 \%$ of all women undergoing general anesthesia. Average actual ablation time was 92 seconds with NovaSure; the Minerva system delivered RF energy for precisely 120 seconds by default. Essentially all procedures in both groups were technically successful. A single woman in the NovaSure group failed the preablation cavity integrity assessment. This patient had a laparoscopic salpingectomy performed immediately before the ablation and failed the cavity integrity assessment, likely due to $\mathrm{CO}_{2}$ escaping through the surgical site of tube removal although no perforation was identified.

A total of 15 women (10 NovaSure and 5 Minerva subjects; $p=0.284$ by Fisher's exact) experienced 16 AEs with onsets occurring within postoperative 14 days (Table 3 ). Three women (two NovaSure and one Minerva; $p=0.999$ ) experienced serious AEs, and all three women were hospitalized: one NovaSure subject experienced severe pain and fever on the day of surgery that resolved by Day 3, after

Table 2 Diagnostic and operative parameters and observations

\begin{tabular}{|c|c|c|c|c|c|}
\hline Parameter & NovaSure & $\mathbf{n}$ & Minerva & $\mathbf{n}$ & p-value ${ }^{a}$ \\
\hline Diagnostic assessments & & 97 & & 92 & \\
\hline \multicolumn{6}{|c|}{ Preoperative endometrial biopsy, n (\%) } \\
\hline Benign & $58(60)$ & & $51(55)$ & & 0.5592 \\
\hline Degenerated endometrium & $2(2)$ & & I (I) & & 0.9999 \\
\hline Endometritis & $I(I)$ & & I (I) & & 0.9999 \\
\hline Hormone effect, exogenous & $\mathrm{I}(\mathrm{I})$ & & $\mathrm{I}(\mathrm{I})$ & & 0.9999 \\
\hline Insufficient sample & $\mathrm{I}(\mathrm{I})$ & & $0(0)$ & & 0.9999 \\
\hline Not performed & $35(36)$ & & $38(4 I)$ & & 0.5501 \\
\hline Hematocrit, mean $\% \pm S D$ & $40.0 \pm 8.4$ & 40 & $38.2 \pm 5.0$ & 33 & 0.2828 \\
\hline US findings & & 94 & & 91 & \\
\hline Uterine length, $\mathrm{cm}$, mean $\pm \mathrm{SD}$ & $8.2 \pm 1.4$ & & $8.3 \pm 1.4$ & & 0.7258 \\
\hline Range, $\mathrm{cm}$ & $5.2-10.6$ & & $4.3-12.4$ & & \\
\hline Women with polyps, $\mathrm{n}(\%)$ & $\mathrm{I}(\mathrm{I})$ & & $3(3)$ & & 0.3581 \\
\hline Women with fibroids, n (\%) & $6(6)$ & & $12(13)$ & & 0.1385 \\
\hline \multicolumn{6}{|l|}{ Procedural parameters } \\
\hline Anesthesia, n (\%) & & 97 & & 92 & \\
\hline General & $43(44)$ & & $32(35)$ & & 0.1852 \\
\hline Spinal & $\mathrm{I}(\mathrm{I})$ & & $0(0)$ & & 0.9999 \\
\hline IV sedation & $49(5 \mathrm{I})$ & & $36(39)$ & & 0.1091 \\
\hline Paracervical block & $53(55)$ & & $48(53)$ & & 0.7716 \\
\hline Uterine sounding depth, $\mathrm{cm}$ & & 32 & & 46 & \\
\hline Mean \pm SD & $8.2 \pm 1.8$ & & $8.6 \pm 0.9$ & & 0.1993 \\
\hline Median (range) & $9(6-10)$ & & $8(6-10)$ & & \\
\hline Ablation time, seconds ${ }^{b}$ & & 94 & & 92 & \\
\hline Mean \pm SD & $92 \pm 24$ & & $120 \pm 0$ & & $<0.000$ I \\
\hline Median (range) & $93(30-120)$ & & - & & \\
\hline
\end{tabular}


Table 3 Adverse events with onset occurring within 14 days after ablation

\begin{tabular}{lll}
\hline Event description & NovaSure & Minerva \\
\hline Bleeding, vaginal & $\mathrm{I}$ & 0 \\
Fever, with pain $^{\mathrm{a}}$ & $\mathrm{I}$ & 0 \\
Nausea & 3 & 0 \\
Pain, abdominopelvic & 3 & 2 \\
Renal failure, acute & 0 & $\mathrm{I}$ \\
Urinary tract infection & 0 & $\mathrm{I}$ \\
Vaginosis, malodorous discharge & 2 & 0 \\
Vomiting & 0 & $\mathrm{I}$ \\
\hline
\end{tabular}

Note: ane NovaSure subject experienced pain and fever together, categorized in unity as both severe and serious.

receiving antibiotics. Another NovaSure subject had moderate vaginal bleeding that began on the day of surgery and spontaneously resolved the following day, after hospitalization for observation. One Minerva subject was admitted for acute renal failure secondary to dehydration of unknown cause, on Day 6, which resolved by the following day after receiving intravenous fluids.

A total of five additional gynecologic procedures were performed in four NovaSure subjects and four procedures in three Minerva subjects $(p>0.05)$. In the NovaSure group three women had hysterectomies, one of which was performed concurrently with left salpingo-oophorectomy and right salpingectomy; a fourth NovaSure woman underwent hysteroscopy with dilation and curettage (D\&C). In the Minerva group, three women had postablation interventions charted; two women had hysterectomies, one of which was associated with transfusion of two units of blood, and a third Minerva woman underwent concurrent hysteroscopy/ D\&C/polypectomy. Another Minerva patient later reported having had a postablation hysterectomy, bringing the total number of postablation hysterectomies to three in each treatment group.

Subjects in the NovaSure and Minerva groups were queried about their experiences at a similar average interval beyond their ablation date (337 and 343 days, respectively; Table 4). Subjects were asked to rate their menstrual bleeding after endometrial ablation as either "No bleeding", "Spotting", "Light bleeding", "Normal menses", or "Heavy bloodflow". The self-reported amenorrhea rate (answering "No bleeding") at the time of survey was significantly higher after NovaSure ablation (64\%, 62/97 women) than after Minerva ablation $(42 \%, 39 / 92$ women; $p=0.004)$. Clinical success rates, defined as normal-to-no bleeding, were similarly $97 \%$ in the

Table 4 Patient questionnaire responses

\begin{tabular}{|c|c|c|c|c|c|}
\hline Parameter & Post-NovaSure & $\mathbf{n}$ & Post-Minerva & $\mathbf{n}$ & $p$-value \\
\hline Days since procedure ${ }^{\mathrm{a}}$ & & 97 & & 92 & \\
\hline Mean \pm SD & $336.7 \pm 116.1$ & & $342.8 \pm 119.7$ & & 0.7225 \\
\hline Range & $137-532$ & & $145-504$ & & \\
\hline Bleeding level, n (\%) & & 97 & & 92 & \\
\hline Amenorrhea & $62(63.9)$ & & $39(42.4)$ & & 0.0036 \\
\hline Hypomenorrhea & $27(27.8)$ & & $37(40.2)$ & & \\
\hline Eumenorrhea & $5(5.2)$ & & $9(9.8)$ & & \\
\hline Menorrhagia & $3(3.1)$ & & $7(7.6)$ & & \\
\hline Success, none-to-normal bleeding, n (\%) & $94(96.9)$ & 97 & $85(92.4)$ & 92 & 0.2039 \\
\hline Menstrual pain, postablation, yes, n (\%) & $20(20.8)$ & 96 & $38(4 \mid .3)$ & 92 & 0.0027 \\
\hline Postablation pain level, $(0-10)^{\mathrm{b}}$ & $4.3 \pm 3.0$ & 20 & $4.3 \pm 2.6$ & 38 & 0.9271 \\
\hline \multicolumn{6}{|l|}{ PMS severity } \\
\hline Ablation result, $\mathrm{n}(\%)$ & & 71 & & 70 & \\
\hline Much improved & $50(70.4)$ & & $31(44.3)$ & & 0.0022 \\
\hline Somewhat improved & $10(14.3)$ & & $16(22.9)$ & & \\
\hline No change & $9(12.7)$ & & $20(28.6)$ & & \\
\hline Somewhat worsened & $0(0.0)$ & & $2(2.9)$ & & \\
\hline Much worsened & $2(2.8)$ & & $\mathrm{I}(\mathrm{I} .4)$ & & \\
\hline Any improvement & $60(84.5)$ & & $47(67.1)$ & & 0.0187 \\
\hline Impact of bleeding on QoL & & 95 & & 90 & \\
\hline Score $0-5$ ( $5=$ maximum impact $)$ & $0.3 \pm 0.9$ & & $0.7 \pm 1.3$ & & 0.0120 \\
\hline
\end{tabular}

Notes: Values are presented as mean \pm SD unless otherwise indicated. Continuous variables were assessed by two-tailed t-test, with $p$-values calculated before rounding measured values to a single decimal place; categorical variables comparing events at a single time point were analyzed with Fisher's exact test; categorical parameters comparing events within one treatment group before and after ablation were evaluated using McNemar's test. 'Interval between ablation procedure and survey was taken from patient records; all other values were patient-reported. 'Menstrual pain level reported by women that had postablation menstrual pain; pain scale is a 0 -I0-point scale with 0 indicating no pain and 10 indicating worst pain imaginable. Bolded $p$-values highlight statistically significant differences.

Abbreviations: AUB, abnormal uterine bleeding; PMS, premenstrual syndrome; QoL, quality of life. 
NovaSure group and $92 \%$ of Minerva subjects. Mean days per cycle with any reported bleeding were comparably reduced in both groups, from 9.0-9.5 days per cycle before treatment to 4.8-5.5 days/cycle after ablation. Diminished bleeding after ablation was reflected in a reduction in the combined number of tampons and pads used daily during any bleeding days within a cycle; in NovaSure subjects, sanitary product use declined by $78 \%$ and in Minerva subjects the reduction was $61 \%$. The self-reported number of tampons and pads used per bleeding day after ablation was significantly fewer (49\%) in the NovaSure group compared to the Minerva group (2.4 and 4.7 per day, respectively; $p=0.049$ ).

A comparable $84 \%$ of both NovaSure and Minerva women reported having menstrual pain at baseline ( $p=0.999)$; the postablation incidence of menstrual pain was significantly lower in the NovaSure group (21\% reporting pain) versus the Minerva group (41\%; $p=0.003$; Table 4). Preoperatively, a similar $73 \%$ of NovaSure subjects and $76 \%$ of Minerva subjects experienced premenstrual syndrome (PMS) ( $p=0.739)$. After NovaSure ablation, $85 \%$ of women who initially experienced PMS reported that their symptoms were either "somewhat improved" or "much improved" versus "no change" or any measure of worsening. In the Minerva group, 68\% of women with prior PMS reported improvement postoperatively, a significantly lower proportion than NovaSure ( $p=0.019)$. Preoperatively, the negative impact of menstrual bleeding on subject QoL, using a 0-5 scale with

Table 5 Satisfaction survey of patients who underwent endometrial ablation for AUB

\begin{tabular}{|c|c|c|c|c|c|}
\hline Parameter n (\%) & $\begin{array}{l}\text { NovaSure } \\
\text { (\%) }\end{array}$ & $\mathbf{n}$ & $\begin{array}{l}\text { Minerva } \\
\text { (\%) }\end{array}$ & $\mathbf{n}$ & $p$-value \\
\hline $\begin{array}{l}\text { Procedure/perioperative } \\
\text { experience? }\end{array}$ & & 97 & & 91 & \\
\hline Very satisfied & $72(74.2)$ & & $63(69.2)$ & & 0.5172 \\
\hline Satisfied & $17(17.5)$ & & $20(22.0)$ & & \\
\hline Neutral & $\mathrm{I}(\mathrm{I} .0)$ & & $5(5.5)$ & & \\
\hline Dissatisfied & $5(5.2)$ & & $0(0.0)$ & & \\
\hline Very dissatisfied & $2(2.1)$ & & $3(3.3)$ & & \\
\hline Ablation results & & 97 & & 92 & \\
\hline Very satisfied & $79(81.4)$ & & $60(65.2)$ & & 0.0135 \\
\hline Satisfied & $12(12.4)$ & & $12(13.0)$ & & \\
\hline Neutral & $2(2.1)$ & & $9(9.8)$ & & \\
\hline Dissatisfied & $3(3.1)$ & & $9(9.8)$ & & \\
\hline Very dissatisfied & $\mathrm{I}(\mathrm{I} .0)$ & & $2(2.2)$ & & \\
\hline Recommend procedure & & 96 & & 92 & \\
\hline to a friend? & & & & & \\
\hline Definitely & $88(91.7)$ & & $72(78.3)$ & & 0.0132 \\
\hline Probably & $5(5.2)$ & & $5(5.4)$ & & \\
\hline Unsure & $\mathrm{I}(1.0)$ & & $7(7.6)$ & & \\
\hline Probably not & $\mathrm{I}(\mathrm{I} .0)$ & & $4(4.4)$ & & \\
\hline Definitely not & $\mathrm{I}(\mathrm{I} .0)$ & & $4(4.4)$ & & \\
\hline
\end{tabular}

Notes: Bolded $p$-values highlight statistically significant differences.

Abbreviation: $A \cup B$, abnormal uterine bleeding.
5 being maximal impact, did not significantly differ between NovaSure women and Minerva women (4.0 and 3.6 points, respectively; $p=0.075)$. Endometrial ablation markedly lowered the impact of menstrual bleeding on subject QoL in both groups, but the average postoperative impact score was significantly improved (lower) in NovaSure ( 0.3 points) versus Minerva subjects ( 0.7 points; $p=0.012)$.

When queried about overall satisfaction with the ablation procedural and perioperative experience, an equivalent $91 \%$ of both NovaSure and Minerva subjects reported being either "very satisfied" or "satisfied" versus feeling "neutral" or any measure of "dissatisfied" ( $p=0.802$; Table 5). When asked about the clinical outcomes after ablation, a significantly larger $81 \%$ proportion of NovaSure subjects were "very satisfied" with postoperative menstrual issues compared to $65 \%$ of Minerva subjects ( $p=0.014)$. This difference was maintained when "satisfied" and "very satisfied" groups were pooled together and compared against the cumulative proportion of women reporting feeling "neutral" or any level of "dissatisfied"; in this instance, $94 \%$ of NovaSure subjects reported some measure of satisfaction with results versus $78 \%$ of Minerva subjects ( $p=0.003$ ). The $92 \%$ proportion of NovaSure subjects who said they would "definitely recommend the procedure to a friend" was significantly larger than the $78 \%$ of Minerva subjects who would definitely recommend $(p=0.013)$.

\section{Discussion}

AUB affects many premenopausal women and negatively impacts QoL. ${ }^{1,2}$ Hysterectomy is the definitive treatment for AUB, but is invasive and carries substantial risk of early AEs including infection, bladder and bowel perforation and thromboembolism, and long-term incidence of pelvic prolapse and cardiovascular disease. ${ }^{4-6}$ Medical approaches to conservatively manage AUB are often unsuccessful, have their own risk of complications, and require treatment until menopause, which can be both burdensome and costly. ${ }^{3}$ Second-generation, uterus-sparing surgical approaches to AUB include transvaginally delivering heat, microwave, laser, or RF energy to ablate the endometrium and thereby ameliorate dysregulated bleeding. ${ }^{7-9}$ The current study identified significant differences in bleeding and QoL outcomes in women whose AUB was treated by endometrial ablation using either the NovaSure or the Minerva system.

The self-reported 11-12-month amenorrhea incidence was increased in both treatment groups, but the final value was $52 \%$ higher in NovaSure subjects than in Minerva subjects. The $64 \%$ NovaSure amenorrhea rate in this study correlates well with the previously reported postoperative 12 -month amenorrhea incidences ranging from $40 \%$ to $58 \%$ 
after NovaSure ablation. ${ }^{12-17}$ The current self-reported $42 \%$ post-Minerva amenorrhea rate, however, is appreciably lower than the $70 \%$ and $72 \%$ rates previously reported at 12 months in two Minerva studies with similar cohort characteristics as ours. ${ }^{18,19}$ Differences in 12-month amenorrhea rates might depend on the method used to assess bleeding. The earlier single-arm pivotal Minerva study used a semiquantitative pictogram bleeding assessment while the subsequent Minerva randomized controlled trial (RCT) used a quantitative alkaline hematin assay. The pictogram tool has similar positive predictive value $(91 \%)$ versus the alkaline hematin assay for identifying excessive menstrual bleeding (ie, $>80 \mathrm{~mL}$ loss per cycle), although it tends to underestimate blood loss in highly saturated feminine sanitary products. ${ }^{20}$ While the alkaline hematin assay accurately quantifies blood within the working limits of the test, it is important to note that the assay's validated lower limit of quantification, per the manufacturer and operator of the Minerva RCT analysis, is $2.5 \mathrm{~mL}$ blood. ${ }^{21}$ The absolute lower limit of detectable blood with the assay is not reported. Care must be taken not to miscategorize very mildly yet visibly blood-stained sanitary products that register below alkaline hematin assay limits of detection, because this could falsely increase the proportion of women that is reported to have achieved amenorrhea. Although the alkaline hematin assay has great experimental utility, its expense, requisite use of temporally matched patient blood samples for internal controls, and the inconvenient requirement that women save and submit all of their sanitary products from a complete cycle, with no losses or omissions, together limit its clinical diagnostic utility. Additionally, up to $12 \%$ of menstrual blood could be lost extraneously and not be measured. ${ }^{22}$ The current study relied on patient reporting of their perceived menstrual bleeding burden before and after endometrial ablation. This approach, though qualitative, well reflects the real-world experience of these women, and questionnaire-based estimations of menstrual bleeding are both practical and reliable, particularly when trying to unequivocally identify complete bleeding cessation. ${ }^{23}$ The current survey questions closely mimicked those in the Menstrual Bleeding Questionnaire, an instrument that has been validated for its ability to differentiate women with versus without self-reported AUB. ${ }^{24}$ Similar patient surveys have been used by others in retrospective cohort studies to assess bleeding outcomes and satisfaction level in women who underwent ablation for AUB. ${ }^{25-27}$ There was no indication that initial bleeding pattern cyclicity affected treatment outcomes after ablation, in line with other observations. ${ }^{28,29}$ The clinical success rate, defined as normalized-to-no bleeding, was similarly excellent $(>90 \%)$ after either treatment according to patient reporting at an average of 11.3 months postablation. In women with any measure of ongoing bleeding, the patient-reported average number of bleeding days per cycle was similarly reduced with NovaSure and Minerva; however, reported daily sanitary product use was significantly lower in NovaSure subjects. Thus, in women with any recalcitrant bleeding, although the menstrual duration did not differ according to treatment, the menstrual bleeding burden using tampon and pad use as a proxy measurement was approximately half in NovaSure subjects compared to Minerva subjects.

Endometrial ablation is known to improve PMS symptoms. ${ }^{18,19,30}$ NovaSure ablation was also associated with a more pronounced reduction in PMS symptoms than Minerva treatment, with significantly more NovaSure women reporting reduced symptoms at 12 months; $85 \%$ of NovaSure subjects versus $67 \%$ of Minerva subjects experienced improvement. An earlier study that focused on ablation effects on PMS reported that $97 \%$ of women with PMS had symptom improvement after NovaSure ablation at a mean postoperative 5.5 months, which was a statistically similar proportion as the current value $(p=0.057) .{ }^{31}$ The prior Minerva single-arm study reported that $81 \%$ of women with preablation PMS had symptom improvement at 12 months. ${ }^{18}$ However, only 54\% of women with PMS experienced symptom improvement in the subsequent Minerva RCT. ${ }^{19}$ Thus, the $67 \%$ of Minerva subjects whose PMS symptoms were improved in the current study is almost the exact average of previously reported values. The proportion of women reporting menstrual pain 12 months after ablation was approximately twofold higher in the Minerva group versus NovaSure subjects, and this difference was significant. Women with AUB frequently report a markedly compromised QoL because of their symptoms, which can restrict physical activities and engagement in social/leisure activities. ${ }^{2,32}$ Women who were treated with NovaSure reported much better menstrual-related QoL after 12 months than did women who underwent Minerva ablation. An equivalent majority of women reported satisfaction with their ablation procedure, independent of which system was used. However, a significantly larger proportion of women in the NovaSure group was both satisfied with their overall results and was more likely to recommend the treatment to a friend than in the Minerva group.

The gold-standard surgical intervention for AUB is hysterectomy, but, compared to ablation, is associated with a significantly greater risk of infection, hemorrhage and damage to nontarget organs, and also a longer recovery time. ${ }^{4}$ Both of the endometrial ablation systems used in the current study provide the level of safety expected of modern endometrial 
ablative procedures, although the NovaSure system has a much longer record of post-market safety surveillance. ${ }^{17,33}$ The number of AEs in the current study was low and did not significantly differ between treatments. Two serious AEs occurred in the NovaSure group (vaginal bleeding and fever with pain), and one occurred in the Minerva arm (renal failure secondary to dehydration). The number of women that progressed to hysterectomy did not differ by treatment. However, the limited number of subjects and brief tracking duration in this study did not permit a rigorous safety assessment.

We achieved the main goal of this study, which was to assess and compare bleeding outcomes in women who underwent endometrial ablation with the NovaSure versus the Minerva RF ablation systems. We acknowledge, however, the limitations of retrospective assessments and the potential for bias introduction that is inherent to all subject surveys. We think that the very close matching of our two study groups' characteristics, including the dates of operation and procedure-to-survey intervals, greatly reduced the likelihood of unbalanced bias introduction. We also recognize that the study population was $93 \%$ Caucasian, which is skewed from the national demographics in the USA. Findings from this study are generalizable to premenopausal women with AUB who match the demographics of the study population. Planned future studies should include RCTs to provide additional evidence of any outcome variation after endometrial ablation using different systems.

Overall bleeding reduction in premenopausal women with AUB was excellent with either endometrial ablation system; however, the NovaSure system resulted in a higher patient-reported 1-year amenorrhea rate, and NovaSuretreated women with any residual bleeding used fewer pads and tampons than Minerva-treated women. Additionally, NovaSure subjects reported better menstrual-related QoL and PMS symptom alleviation, and greater satisfaction with outcomes than Minerva-treated women.

\section{Acknowledgments}

This study was funded by Hologic Inc. The authors thank Matthew Silverman, MSci, PhD (Biomedical Publishing Solutions, Delray Beach, FL) for scientific, analytical, and editing services in preparing this manuscript, and Christine Martunas, CCRP, for rigorous data compilation, quality control, and analysis.

\section{Disclosure}

All authors were principal investigators in the current study and received compensation from Hologic for participation.
Dr Scordalakes is a speaker for Shionogi \& Co. Ltd., and a shareholder of The Women's Hospital (Newburgh, IN). Dr delRosario is on the speakers' bureau for Minerva Surgical, Inc. Dr Stankiewicz is a consultant for Ethicon and for Myriad Genetics. The authors report no other conflicts of interest in this work.

\section{References}

1. Committee on Practice Bulletins - Gynecology. Practice bulletin no. 128: diagnosis of abnormal uterine bleeding in reproductive-aged women. Obstet Gynecol. 2012;120(1):197-206.

2. Kuppermann M, Varner RE, Summitt RL Jr, et al; Ms Research Group. Effect of hysterectomy vs medical treatment on healthrelated quality of life and sexual functioning. JAMA. 2004;291(12): $1447-1455$

3. Bradley LD, Gueye NA. The medical management of abnormal uterine bleeding in reproductive-aged women. Am J Obstet Gynecol. 2016; 214(1):31-44.

4. Wallace SK, Fazzari MJ, Chen H, Cliby WA, Chalas E. Outcomes and postoperative complications after hysterectomies performed for benign compared with malignant indications. Obstet Gynecol. 2016; 128(3):467-475.

5. Thakar R, Sultan AH. Hysterectomy and pelvic organ dysfunction. Best Pract Res Clin Obstet Gynaecol. 2005;19(3):403-418.

6. Ingelsson E, Lundholm C, Johansson AL, Altman D. Hysterectomy and risk of cardiovascular disease: a population-based cohort study. Eur Heart J. 2011;32(6):745-750.

7. Daniels JP, Middleton LJ, Champaneria R, et al; International Heavy Menstrual Bleeding IPD Meta-analysis Collaborative Group. Second generation endometrial ablation techniques for heavy menstrual bleeding: network meta-analysis. BMJ. 2012;344:e2564.

8. Lethaby A, Penninx J, Hickey M, Garry R, Marjoribanks J. Endometrial resection and ablation techniques for heavy menstrual bleeding. Cochrane Database Syst Rev. 2013;8:CD001501.

9. Fergusson RJ, Lethaby A, Shepperd S, Farquhar C. Endometrial resection and ablation versus hysterectomy for heavy menstrual bleeding. Cochrane Database Syst Rev. 2013;11:CD000329.

10. NovaSure ${ }^{\circledR}$ Impedance Controlled Endometrial Ablation System. Summary of Safety and Effectiveness Data. Palo Alto, CA: Novacept Incorporated/Interlace Medical; prepared September 28, 2001. Available from: http://www.accessdata.fda.gov/cdrh_docs/pdf/P010013b. pdf. Accessed October 9, 2017.

11. Minerva ${ }^{\mathrm{TM}}$ Endometrial Ablation System. Summary of Safety and Effectiveness Data. Redwood City, CA: Minerva Surgical, Incorporated; July 27, 2015. Available from: https://www.accessdata.fda.gov/ cdrh_docs/pdf14/p140013b.pdf. Accessed October 9, 2017.

12. Rubino RJ, Roy KH, Presthus J, Trupin S. Abnormal uterine bleeding control by sequential application of hysteroscopic lesion morcellation and endometrial ablation. J Reprod Med. 2017;62:102-110.

13. Clark TJ, Samuel N, Malick S, Middleton LJ, Daniels J, Gupta JK. Bipolar radiofrequency compared with thermal balloon endometrial ablation in the office: a randomized controlled trial. Obstet Gynecol. 2011; 117(1):109-118.

14. Baskett TF, Clough H, Scott TA. NovaSure bipolar radiofrequency endometrial ablation: report of 200 cases. J Obstet Gynaecol Can. 2005;27(5):473-476.

15. Busund B, Erno LE, Grønmark A, Istre O. Endometrial ablation with NovaSure GEA, a pilot study. Acta Obstet Gynecol Scand. 2003; 82(1):65-68.

16. Gallinat A, Nugent W. NovaSure impedance-controlled system for endometrial ablation. J Am Assoc Gynecol Laparosc. 2002;9(3): 283-289.

17. Gimpelson RJ. Ten-year literature review of global endometrial ablation with the NovaSure ${ }^{\circledR}$ device. Int $J$ Womens Health. 2014;6:269-280. 
18. Laberge P, Garza-Leal J, Fortin C, et al. One-year follow-up results of a multicenter, single-arm, objective performance criteria-controlled international clinical study of the safety and efficacy of the Minerva Endometrial Ablation System. J Minim Invasive Gynecol. 2015;22(7): 1169-1177.

19. Laberge P, Garza-Leal J, Fortin C, et al. A randomized controlled multicenter US Food and drug administration trial of the safety and efficacy of the minerva endometrial ablation system: one-year follow-up results. J Minim Invasive Gynecol. 2017;24(4):124-132.

20. Larsen L, Coyne K, Chwalisz K. Validation of the menstrual pictogram in women with leiomyomata associated with heavy menstrual bleeding. Reprod Sci. 2013;20(6):680-687.

21. KCAS Biomarker and Bioanalytical Services. Assay Performance Specifications. Menstrual blood loss quantitated as alkaline hematin. Available from: http://kcasbio.com/wp-content/uploads/2014/12/Alkaline-Hematin-Assay-Performance.pdf. Accessed October 9, 2017.

22. Hurskainen R, Teperi J, Turpeinen U, et al. Combined laboratory and diary method for objective assessment of menstrual blood loss. Acta Obstet Gynecol Scand. 1998;77(2):201-204.

23. Smithling KR, Savella G, Raker CA, Matteson KA. Preoperative uterine bleeding pattern and risk of endometrial ablation failure. Am J Obstet Gynecol. 2014;211(5):556.e1-e6.

24. Matteson KA, Scott DM, Raker CA, Clark MA. The menstrual bleeding questionnaire: development and validation of a comprehensive patient-reported outcome instrument for heavy menstrual bleeding. BJOG. 2015;122(5):681-689.

25. MullerI, van der Palen J, Massop-HelminkD, Vos-deBruin R, Sikkema JM. Patient satisfaction and amenorrhea rate after endometrial ablation by ThermaChoice III or NovaSure: a retrospective cohort study. Gynecol Surg. 2015;12(2):81-87.
26. Fischer F, Klapdor R, Gruessner S, Ziert Y, Hillemanns P, Hermann H. Radiofrequency endometrial ablation for the treatment of heavy menstrual bleeding among women at high surgical risk. Intl J Gynecol Obstet. 2015;131(2):123-128.

27. Elmardi S, Furara S, Khan F, Hamza M. NovaSure impedance controlled system for endometrial ablation: the experience of the first UK reference centre. J Obstet Gynaecol. 2009;29(5):419-422.

28. Hokenstad AN, El-Nashar SA, Khan Z, Hopkins MR, Famuyide AO. Endometrial ablation in women with abnormal uterine bleeding related to ovulatory dysfunction: a cohort study. J Minim Invasive Gynecol. 2015;22(7):1225-1230.

29. Toxqui L, Pérez-Granados AM, Blanco-Rojo R, Wright I, Vaquero MP A simple and feasible questionnaire to estimate menstrual blood loss: relationship with hematological and gynecological parameters in young women. BMC Womens Health. 2014;14:71.

30. Waddell G, Pelletier J, Desindes S, Anku-Bertholet C, Blouin S, Thibodeau D. Effect of endometrial ablation on premenstrual symptoms. J Minim Invasive Gynecol. 2015;22(6):631-636.

31. Lukes AS, McBride RJ, Herring AH, Fried M, Sherwani A, Dell D. Improved premenstrual syndrome symptoms after NovaSure endometrial ablation. J Minim Invasive Gynecol. 2011;18(5):607-611.

32. Karlsson TS, Marions LB, Edlund MG. Heavy menstrual bleeding significantly affects quality of life. Acta Obstet Gynecol Scand. 2014; 93(1):52-57.

33. Brown J, Blank K. Minimally invasive endometrial ablation device complications and use outside of the manufacturers' instructions. Obstet Gynecol. 2012;120(4):865-870.
International Journal of Women's Health

\section{Publish your work in this journal}

The International Journal of Women's Health is an international, peerreviewed open-access journal publishing original research, reports, editorials, reviews and commentaries on all aspects of women's healthcare including gynecology, obstetrics, and breast cancer. The manuscript management system is completely online and includes

\section{Dovepress}

a very quick and fair peer-review system, which is all easy to use. Visit http://www.dovepress.com/testimonials.php to read real quotes from published authors. 